\title{
The Role of Learning Resource Centers at the Northern Border University in Increasing the Academic Achievement in English Language Courses
}

\author{
Yaser Mohammad Al Sawy ${ }^{1}$ \& Mubarak Altwaiji ${ }^{2}$ \\ 1 Assistant Professor of Library and Information Technology, Faculty of Education and Arts, Education \\ Technology Department, Northern Border University, Saudi Arabia \\ ${ }^{2}$ Assistant Professor of English, Northern Border University, Saudi Arabia \\ Correspondence: Yaser Mohammad Al Sawy, Northern Border University, Saudi Arabia. E-mail: \\ yaseralsawy@yahoo.com; srd4@nbu.edu.sa
}

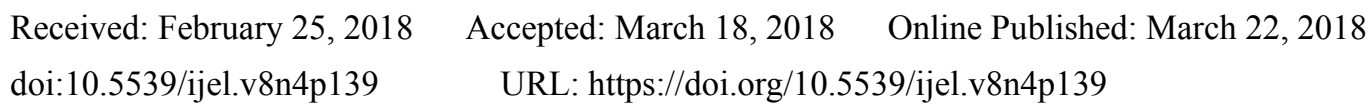

\begin{abstract}
The study aims at understanding the relationship between the use of IT applications in the Learning Resources Centers (henceforth, LRCs) at the university and increasing the academic achievement of the English language students at the Faculty of Education and Literature at the Northern Border University? The researcher relied on the research methodology of the field study, which allowed him to collect the views of a random sample of the English language learners at the university to measure and analyze the effectiveness of the use of IT within the LRCs. The study showed that the IT within the LRCs is one of the most important strategic resources at the level of educational institutions and the main factor in the development of its sectors. There is an interest from the Northern Border University on upgrading and supporting the IT infrastructure, especially in education for it is the basis for community development. A high proportion of English Language students at the university are keen on using and applying many of the technological learning media within the LRCs as a constitutive factor in understanding mental processes such as visualization, thinking, learning and creativity which is the first step towards knowledge and innovation.
\end{abstract}

Keywords: learning resource centers, information technology, educational media, university education, academic achievement, English language courses

\section{Introduction}

The LRC is an important resource that connects the educational environment of the educational institution with its social environment and enhances the concepts of modern education. The LRC also creates the appropriate facilities to improve the learning process in the fields of study. It provides a range of functions, processes, activities and a series of library and information services for the learner and teacher. In fact, it provides a good and rich collection of learning resources and information in all printed forms in order to develop the educational process (Deng, 2016).

The LRC should play the role of supplying traditional and non-traditional sources of information. This makes the teacher and learner aware of all updates in intellectual production. If we tried to make these resources available in their traditional form only as in libraries, we would fail. The LRC also organizes and facilitates access to such information in less time and with the minimum effort (Lo, 2013).

LRCs represent a giant leap in the design and implementation of the modern educational tools. Indeed, they are concerned with the integration of technology with education and the use of modern technological devices. These latters facilitate the transfer of information to the learner and exchange the information with everyone according to a scientific educational vision that can be developed through constructive criticism to reach the desired level (Alenezi, 2017).

LRCs have recently been subjected to multiple attempts to reduce their role and functions. Thus, Information technology tools have been an important factor for the emergence of these centers and their importance in the educational process (Rolland, 1983). 
The concept of the LRC can be understood as:

It is an educational environment that contains many types of learning resources, where the learner is provided with opportunities to acquire skills and experience to enrich his knowledge through self-learning.

The LRC is defined as a site in the educational institution that provides services to teachers, students, administrators and others. These services include the provision of various printed and non-printed and electronic learning resources, the availability of the information network and other services such as the production of resources, vocational training, Processes, information and specific tasks, with a qualified specialist in order to provide a resource-rich learning environment and employ modern teaching and learning methods based on the integration of ICT into the learning process (Alexander, 2013).

It is also known as a scientific environment that contains various types of printed, audio and visual knowledge and the means of its use, which the learner experiences, processes and interacts with. It allows him to acquire knowledge, experience and skills and to enrich his knowledge through self-learning supervised by specialists who facilitate the conditions of dealing with all facilities of these centers freely and positively.

Thus, all the arranged information resources in buildings provide all appropriate facilities for the advancement of learning and education. It is noteworthy to mention that the center includes the building, the human cadres, and all information sources.

Based on the previous definitions, the researcher believes that LRC is an educational environment that has a suitable climate for learning. LRC has a vital role in education in modern times, for it contains many varieties of information programs, equipment, tools and devices.

The use of these resources could be in a traditional printed form or in an electronic form such as CDs, databases and multiple learning resources. A highly trained professional manages and develops these processes.

What do we mean by technology?, The term "technology" stems from the Greek word "Techne", which means art or skill or the Latin word "Texere", which means construction or weaving and the Greek word "loges", which means science or study. Thus, the word technology refers to science or skills or in other words to study skills logically to perform a specific function (Kurymbayev, 2016).

The following phenomena have transformed technology into a power that lead to profound change in education:

- Multimedia, which broke the barriers between the different multimedia, communication and information.

- Mobile technology: It freed individuals from the constraints of being in a particular place to communicate and access scientific information. It also made it possible for individuals in remote and isolated areas to access the best educational institutions.

- The Internet, which changed the terms of exchange between individuals, and facilitated access to information and knowledge.

- Communication revolution, which allows the transmission of larger amounts of information every day through a complex network of media and terrestrial and marine optical cables. This provided the possibility of an efficient transfer of a large amount of information, including the facilities to deliver lectures in remote areas.

The knowledge community has broken barriers that substantially limited the access of most people to information, knowledge and culture, which helps to pave the way for new creations in science and knowledge.in this respect, developed societies give broad attention to supporting programs that provide an enabling environment for all individuals to have as much access as possible to modern developments In science and knowledge, through the right of free use of all citizens with the latest and most advanced technology.

In a recent study on the effect of Teaching and Learning Resources on the achievement of the students which carried out by (Okongo, 2015) the authors note that institutions can use the learning resources to "accommodate all learners regardless of their physical, intellectual, social, emotional, linguistic challenges", Their study recommended implementation of an "adequate teaching and learning resources" that "should be provided to ensure effective implementation of inclusive education", In a study titled "Impact Of School Library Services On Achievement And Learning" (Williams, 2001), found that "there are associated key factors of collection levels, library staffing levels and collaboration between the librarian and teacher. Training of teachers and librarians is demonstrated to raise mutual understanding of each other's contribution and roles", The authors concluded that the use of resources helps "developing skills through in-service and initial training will lead to greater understanding, improved performance and increased confidence". 


\subsection{Research Problematic}

There is no doubt that simply buying the latest IT applications by the Northern Border University for the LRCs is not helpful as long as there is no understanding of how to benefit from them in developing and improving teachers' and students' performance, hence, the researcher noted that despite the university's interest in the development and implementation of information technology in all levels of education, there is little research on this matter, This led the researcher to evaluate the university's efforts to benefit from the applications of information technology within the LRCs and their influence on the beneficiaries in the institution through a specialized study about The English language students.

Therefore, the research problematic of this study can be summarized in the following question:

- To what extent can IT applications in the LRCs contribute to improving the institutional performance and increasing academic achievement among English language students in the Faculty of Education and Arts and the Deanship of the preparatory year?

\subsection{Research Objectives}

The study aims at understanding the relationship between the uses of IT applications in the learning resources centers at the Northern Border University and increasing the educational achievement of its students. As well its influence on the development of the beneficiaries through reviewing the components of these tools and analyzing their performance in order to determine their effectiveness based on the opinions of a random sample of English language learners at the Faculty of Education and Arts, and the preparatory year (Archibald, 2004).

The main objectives of this study are:

1) Learn about the latest IT applications used for service delivery in the LRCs.

2) Identify the efforts of the Northern Border University to benefit from the various applications of information technology in the LRCs.

3) Achieve specific results by which the effectiveness of the use of information technology in the LRCs can be assessed to improve the institutional performance of the Northern Border University.

\subsection{Research Questions}

The study also seeks to answer the following research questions:

1) What are the IT hubs within the LRCs?

2) Is there a link between the use of IT within the learning resources centers of the Northern Border University and the improvement of the English Language student's academic achievement?

3) What IT tools are used in the LRCs at the Northern Border University?

4) What is the effect of tools implementation on increasing academic achievement among students of English language at the Faculty of Education and Arts and the preparatory year of the Northern Border University?

\section{Research Methodology}

The researchers used the descriptive approach as a research method for studying the phenomenon. This approach describes the phenomenon neatly in a realistic method in which data is collected from the field and analyzed based on the relationships between the available components. Further, in order to achieve the main goal of the research, the researchers built questionnaire composed of 10 questions for testing three skills: first is skill of finding data partiality, second is the skill of differentiation between opinion and fact and third is the skill of differentiation between the right and the wrong answers. Based on this, the researchers applied the study on 30 students who are not from the sample study.

The researchers will use the following data collection tools in order to obtain accurate data that may support or criticize the study hypotheses:

\subsection{Interviews}

Some people were interviewed according to a set of questions prepared in advance by the researchers, which can help to answer the research questions and validate or criticize its hypotheses.

\subsection{Formal Observation}

The researchers observed the learning phenomenon accurately and identified its dimensions in the LRCs and obtained data that allow validating or criticizing the research hypotheses. 


\subsection{Questionnaires}

The questionnaire was used to collect the views of a random sample of the English language students at the university to measure the effectiveness of IT use in the LRCs.

\subsection{Piloting the Questionnaires}

The questionnaire was presented to a small sample of the beneficiaries at the Northern Border University to see how it could cover the aspects of the research study and obtain results that Support or deny the research hypotheses.

Based on this empirical piloting study, the researchers concluded that the questionnaire can be submitted to all members of the sample group.

\section{Discussion and Analysis}

The integration of IT in education is a sign of the development of society. This type of education is characterized by two important variables: relativity and change. The change in the higher education policy has a great impact on the society. In this respect Technology is one of the most important forms of this development in the educational society, with its enormous potential as a mechanism for internal and external communication to disseminate knowledge.

Education as a variable of social transformation or a primary driver of this transformation is the most vulnerable aspects of society. Consequently, the serious changes in the knowledge community will inevitably change the education system, both from the philosophical side and the policy-making in restructuring its institutions and methods (Dee, 2017).

The social transition that will be brought about by information technology is essentially an educational leap. When the importance of natural and material resources is forgotten and knowledge emerges as the most important sources of social forces, the human resource development that produces and employs this knowledge will be the decisive factor in building Knowledge (Ward, 2017).

Thus, education and development overlap in many aspects. Investment in education has become the most important investment in the short and long term. Everyone knows that the fate of nations depends on the creativity of individuals in dealing with the problems and demands of change (Fellenz, 2016).

Despite the specificity of the Saudi society and its established social norms and traditions, the currents of change that have taken place because require that universities enter the twenty-first century based on scientific studies and societal data. This helps to meet the future needs by preparing students to accommodate to future changes, and interact, use them to serve the community through the following concepts: (Al Musawi, 2017).

- Transition from static planning to dynamic planning.

Identifying vision in the educational institutions way of work requires educational planning to solve future problems and crises.

- Transition from technical planning to consultative planning

The interrelation of the educational system with all societal systems and decision-making processes makes planning a wide-ranging participants, beneficiaries and sponsors of the educational system.

- Adopting strategic planning instead of tactical planning.

Strategic planning is a tool for balancing the various educational processes in the short term, while the long term is seen as a tool for achieving the required structural change in the development areas.

This concept entails the need to link educational plans with development plans, and the consequent link between educational policies and comprehensive development policies.

In this sense, the researcher believes that the strategic planning processes require intervention in the educational system processes. This intervention should be followed by a quantitative and qualitative change. This requires awareness of the relations between the outputs of the educational system and the different developmental needs in its social and economic aspects (Tikhonova, 2016).

\subsection{Information Technology at the Northern Border University}

It is well known that information technology is the basis of knowledge economy at the Northern Border University, where students must be able to compile, analyze and interpret data. The universities require skills in self-management, communication, analysis and simulation, as well as basic academic knowledge and specialized skills. Taking into consideration the difficulties facing the full and optimal development of the educational 
system, this task must be introduced through a program supported by the institution to provide assistance to all educational institutions (Xu, 2016).

Information technology is an approach that involves the application of scientific knowledge and empirical data, which aims to improve educational systems in order to be able to solve the needs of learning and education in today's world, based on ICT tools, which are realistic and rational solutions that guide technological intuition towards Research and development.

\subsection{Information Technology Media}

The term media is used to describe the presentation and representation of knowledge, as well as to reorganize it in viewable forms. The distinction between media and technology will inevitably become less important when they are all integrated into a single mechanism. Our world is increasingly integrating ICT into one system including phones, Communications, electronic computers, satellite and wireless and wired telecommunications (Eryilmaz, 2015).

\subsection{Classification of Technological Media}

An important step in selecting appropriate technological media is to distinguish between this technology on a specific basis or more, which can be stated as follows:

One-way or two-way: One of the main ways of distinguishing between technological applications is being One-way or two-way, because the two-way approach allows interactive communication between the academic and the student, and among the students themselves (Mendes, 2015).

Interactivity: The second method of differentiation is interactivity. Although a large number of people imagine that interactive technological media are inevitably two-way, this impression is incorrect, because there are interactive CDs used for education and training, but they cannot be classified as two-way.

Flexibility: Applications that integrate with different technological media, as well as mixing different technological media to use applications. Flexibility varies between applications.

Continuity: There are well designed applications suitable for educational purposes and the objectives of the institution are applied and used now, however these applications must be developed permanently to be compatible with advanced technology and the needs of permanent beneficiaries.

Ease of use, operation and maintenance: There are applications that are easy to operate and use, and others are very complex. When choosing an application, it should be user friendly and easy to maintain, which allows it's widespread to benefit more users.

\subsection{Selection of Educational Media}

The selection of the educational media at the Northern Border University is a difficult task because it depends on a large number of overlapping criteria. The distinction between these media is inaccurate, because they are only complementary media for one another, where a means can be used in a particular position and others in other situations. Therefore the main factor that determines the type of means is the nature of the situation (Gropper, 2016).

In line with the mentioned above, it can be concluded that technology is a systematic way that follows organized knowledge and uses all available resources, whether physical or non-physical, in an efficient manner to achieve the desired degree of perfection or efficiency. Thus, technology has three meanings:

1) Technology as Processes means systematic application of scientific knowledge.

2) Technology as products means instruments, devices and materials resulting from the application of scientific knowledge.

3) Technology as a process and output together, and is used in this sense when the text refers to processes and their outputs together, such as computer technologies.

\subsection{Internet in the LRCs}

The building of networks that penetrate the Internet makes it the smartest, broadest and largest challenge among other forms of media. It could be also the most dangerous at all. What e-mail, sites and multiple search mechanisms, for example, could have done five years ago, what they can do now and what the situation will be like in the next five years? It is clear that many interactive forms will appear and force us to think deeply (Ozkan, 2010).

The greatest challenge for parents and educators is the good preparation of the positive natural and electronic 
environments for the next generations.

\section{Analysis of the Sample Characteristics}

\subsection{In Terms of Type}

The total number of the sample is 109 students (males and females) who were randomly selected from the English language learners at the Faculty of Education and Arts and the Deanship of Preparatory Year at the Northern Border University. The number of male students was 57, which equals $52.3 \%$ and the number of female students was 52 , which is the equivalent of $47.7 \%$.

\subsection{In Terms of the College}

While the number of male students in the English language specialization in the Faculty of Education and Arts was 22 , the number of male students in the preparatory year was 35 students. The number of female students in the English language specialization in the Faculty of Education and Arts was 20 students, whereas at the preparatory year was 32 .

\section{Analysis of Questionnaire Questions}

Table 1. Pearson correlation coefficient for every statement in the second part of the questionnaire

\begin{tabular}{|c|c|c|}
\hline $\mathrm{S}$ & Statement & $\begin{array}{l}\text { Correlation } \\
\text { coefficient }\end{array}$ \\
\hline 1 & What kind of technology is available in the LRC & $* * 0.401$ \\
\hline 2 & $\begin{array}{l}\text { Is the teaching material taught in English courses through the Internet, educational programs and educational } \\
\text { films within the LRC? }\end{array}$ & $* * 0.529$ \\
\hline 3 & What are the scientific materials that are taught in the form of technology within the LRC? & $* * 0.395$ \\
\hline 4 & $\begin{array}{l}\text { Is the university keen to teach the subject of English in one of the traditional forms (models - paintings - maps) } \\
\text { within the LRC? }\end{array}$ & $* * 0.482$ \\
\hline 5 & Is the teaching of the subject in a helpful way in the LRC at the university? & $* * 0.661$ \\
\hline 6 & Is the subject developed continuously to be up-to-date with technology? & $* * 0.862$ \\
\hline 7 & Do you think that using IT in teaching in the LRC helps to increase your academic achievement? & $* * 0.527$ \\
\hline 8 & $\begin{array}{l}\text { What are the most important English language courses that were influenced by those technological devices to } \\
\text { increase the academic achievement? }\end{array}$ & **0.488 \\
\hline 9 & Do you think that the university is keen to apply information technology in the teaching and learning processes? & $* * 0.413$ \\
\hline 10 & Are you satisfied with the IT applications used in the LRC? & $* * 0.434$ \\
\hline
\end{tabular}

If the correlation coefficient value is less than 0.25 , it means that it is low, if its value is between $0.25-0.49$ it mean it is on average. If the value is between $0.50-0.75$, the correlation value is high and the relation is high too. If the value is higher than 0.75 , the correlation value is very high and the relation is very high.

- The first question, what kind of technology is available in the LRC?

a- Audio materials (cassettes): chosen by 19 students (17.43\% of the total sample), divided into 9 male students and 10 female students.

b- Visual materials (silent films, silent video programs): chosen by 11 students $(10.09 \%$ of the total sample), divided into 9 male students and 2 female students.

c- Audio-visual materials (educational films, Audio-visual programs): chosen by 84 students $(77.06 \%$ of the total sample), distributed into 38 male students and 46 female students.

By carrying out the Chi2 test, $\mathrm{P}=0.039$ was found to be less than $\mathrm{P}=0.05$. This means that the differences in ratios are significant, i.e., the gender factor has an effect on the choice of the form of the educational material.

- The second question, is the teaching material taught in English courses through the Internet, educational programs and educational films within the LRC?

- Yes, 82 students answered with 75.23\%, and 27 students (24.77\%) answered no. While 48 students (44.04\%) male student answered no, 34 female students, $31.19 \%$ answered yes, 4 male students by (3.67\%) and 23 female students $(21.1 \%)$. answered no.

After carrying out the Chi2 test, findings showed that $\mathrm{P}=0.033$ is less than $\mathrm{P}=0.05$. This means that the differences in ratios are significant, i.e., the gender factor has an impact on the teaching of educational material through the Internet, educational software and educational films in the classroom. 
- The third question, what are the scientific materials that are taught in the form of technology within the LRC?

A- English Language Skills Courses: 103 students (94.5\%) responded, they are divided into 49 male students (44.95\%) and 54 female students (49.54\%), In the case of the Chi2 test, $\mathrm{P}=0.047$ was found to be less than $\mathrm{P}=$ 0.05. This means that the differences in the ratios are significant, i.e., the gender factor has an impact on the teaching of the English language skills course

B- English language specialty courses: In terms of gender, 56 students (51.38\%) responded, they are divided into 20 male students with $18.35 \%$ and 36 female students with $33.03 \%$, The Chi2 test showed that the value of $\mathrm{P}=$ 0.134 is less than $\mathrm{P}=0.05$. This means that the differences in ratios are not significant, i.e., the gender factor has no effect on English.

The fourth question, is the university keen to teach the subject of English in one of the traditional forms (models - paintings - maps) within the LRC?

- 75 students with (68.81\%) answered with yes and 34 students $31.19 \%$ answered with no, Whereas 32 male students $(29.36 \%)$ responded by yes, 43 female students (39.45\%) responded by yes, While 25 male students $22.94 \%$ answered with no, 9 female students $8.26 \%$ answered with no.

Results from the Chi2 test, exhibited that the value of $\mathrm{P}=0.044$ is less than $\mathrm{P}=0.05$. This means that the differences in the ratios are significant, i.e., the gender factor has an effect on the answer to the teaching of the subject in one of the traditional forms.

- The fifth question, is the teaching of the subject in a helpful way in the LRC at the university?

- In terms of gender: 31 male students (28.44\%) responded by yes and 78 students $(71.56 \%)$ responded by no, 18 male students (16.51\%) and 13 female students (11.93\%) answered with yes, While 39 male students (35.78\%) answered with no, 38 female students $35.78 \%$ answered with no.

In the case of the Chi2 test, $\mathrm{P}=0.037$ is less than $\mathrm{P}=0.05$, which means that the differences in the ratios are significant, i.e., the gender factor has an effect on the teaching of the subject in a helpful way in the LRC.

The sixth question, is the subject developed continuously to be up-to-date with technology?

- In terms of gender: 100 students $91.74 \%$ answered yes, and 9 students $8.26 \%$ responded by no, 50 participants $(45.87 \%)$ in both genders answered yes, While 7 male students $6.42 \%$ responded by no, only 2 female students $1.83 \%$ responded by no, By carrying out the CHI2 test, $\mathrm{P}=0.039$ was found to be less than $\mathrm{P}=0.05$. This means that the differences in the ratios are significant, i.e., the gender factor has an effect on the continuous development and updating of the subject in a technological manner.

- The seventh question, do you think that using IT in teaching in the LRC helps to increase your academic achievement?

- In terms of gender: 107 students $98.17 \%$ answered with yes, but only 2 answered without 2 students $1.83 \%$ responded by no, 56 male student's $51.38 \%$ and 51 female students $46.79 \%$ answered with yes, Only one student $0.92 \%$ answered with no in each gender.

The Chi2 $=0.025$, which is less than $\mathrm{P}=0.05$, means that the differences in ratios are significant, i.e., the gender factor has an effect on the fact that teaching using IT helps to increase students' academic achievement.

- The eighth question, what are the most important English language courses that were influenced by those technological devices to increase the academic achievement?

A: English language skills: 57 students $52.29 \%$ responded, they are divided into 27 male students' $24.77 \%$ and 30 female students $27.52 \%$.

By carrying out the Chi2 test, the value of $\mathrm{P}=0.067$, which is greater than $\mathrm{P}=0.05$, reveals that the differences in ratios are not significant, i.e., the gender factor has no effect on the choice of English language skills.

B- Courses of English specialization: 56 students $51.38 \%$ responded to the question, they are distributed into 23 male students' $21.1 \%$ and 33 female students $30.28 \%$.

The Chi2 test showed that $\mathrm{P}=0.123$ is greater than $\mathrm{P}=0.05$, which entails that the differences in ratios are not significant, i.e., the gender factor has no effect on the English language course.

-The ninth Question, Do you think that the university is keen to apply information technology in the teaching and learning processes?

102 students $93.58 \%$ answered with Yes and 7 students $6.42 \%$ responded by no, 51 male student's $46.79 \%$ and 51 female students $46.79 \%$ answered with yes, Similarly, 7 students $6.42 \%$ in both genders responded by no. 
In the case of the Chi2 test, $\mathrm{P}=0.022$ was found to be less than $\mathrm{P}=0.05$. This means that differences in ratios are significant, i.e., the gender factor has an impact on the interest of the University to apply information technology in the teaching and learning processes.

-The tenth question, Are you satisfied with the IT applications used in the LRC?

In terms of type: while 104 students $95.41 \%$ answered with yes, only 5 students $4.59 \%$ replied by no, 55 male students' $50.46 \%$ and 49 female students $44.95 \%$ answered with yes, 2 male students' $1.83 \%$ and 3 female students $2.75 \%$ answered by no.

In the case of the CHI2 test, $\mathrm{P}=0.025$ is less than the value of $\mathrm{P}=0.05$, which means that the differences in ratios are significant, i.e., the gender factor has an impact on the satisfaction with the implementation of IT applications in the LRC.

\section{Results}

In accordance with the students' views on the applications of information technology and their impact on the achievement of students in English language specialization, the following results can be obtained:

With respect to the characteristics of the study sample: The ratio of the sample between the male students and female students bore some similarities, for males reached $52.3 \%$ compared to $47.7 \%$ for females.

With regard to the questionnaire's results: Concerning the technological form available in the LRC in the University.

A- The use of educational audio materials has declined sharply, reaching $17.43 \%$.

B- The form of visual materials available at the university decreased by $10.09 \%$.

C- The percentage of audio-visual materials rose to $77.06 \%$ of total sample responses. This reflects the university's keenness on the availability of these forms, because they bring modernity and diversity together and encourage students to use them in the LRC.

In terms of teaching the subject through the Internet, educational computer programs and educational films in the LRC, $75.23 \%$ of the total sample responded well, reflecting the keenness of the university and faculty members to use these applications during the educational process.

- Concerning the subjects that are taught through the medium of technology

While English language skills courses increased with $94.5 \%$ of the total sample, the percentage of the use of English language courses dropped with $51.38 \%$ of the total sample.

- In terms of the university's keenness on teaching the subject in one of the traditional forms in the LRC, the students' responses represented an average of $68.81 \%$ of the total sample.

- Regarding the self-teaching of the subject by a teacher in the LRC, the student responses rose very well, reaching $87.16 \%$ of the total sample.

- Unlike other aspects, teaching the subject in a helpful way in the LRC, students' responses of the total sample were very poor $28.44 \%$.

- Regarding the development of the subject matter to be up-to-date with technology in the LRC, the students' responses rose to $91.74 \%$ of the total sample.

Concerning the role of the family in providing the subject technologically at home, the responses of the students were excellent, $90.83 \%$ of the total sample

- In terms of the relationship between the use of IT in the LRC and the improvement of the academic achievement, students' answers with yes increased to make up $98.17 \%$ of the total sample.

- Regarding the subjects that have been influenced by the technological tools in increasing academic achievement.

English language skills courses reached $52.29 \%$ of the total sample.

English language specialty courses also obtained a poor percentage $51.38 \%$ of the total sample.

- In terms of the University's keenness to apply information technology at the university's LRC, the percentage was excellent $93.58 \%$ of the total sample.

- In terms of students' satisfaction with the implementation of IT applications in the LRC, the percentage increased to $95.41 \%$ of the total sample. 


\section{Conclusion}

The present research sought to understand the relationship between the use of IT applications in the Learning Resources Centers at the university and increasing the educational achievement, which leads to the improvement of the university students in knowledge and information. The prosperity and development of the beneficiaries in the knowledge society was measured through reviewing the components of these tools and analyzing their performance, determining their effectiveness by studying a random sample of them. The study also tried to answer the research the research questions and the main research question: Is there a correlation between the use of information technology within the LRCs and increasing the academic achievement of the English language students at the Faculty of Education and Literature at the Northern Border University?

The researcher used different data collection tools such as interviews, formal observations and questionnaires in order to validate data that may support or criticize the study hypotheses. These tools were used to obtain the views of a random sample of the English language students at the university in order to measure the effectiveness of IT use in the LRCs. Based on these empirical findings, the researcher concluded that the use of audio-visual materials helps to meet the needs of students in English language skills courses as well as English language specialty courses. It has been identified also that paying more attention to teaching the subject through the Internet and computer programs in the LRC to ensure that students use these materials and reach an excellent level. While comparing results, it became obvious that to consider the integration of the LRC at all stages of the educational process and the use of IT applications within those LRCs, while increasing the training of the LRC specialists.

\section{Research Recommendations}

Within each of these findings of the study, it is identified that there are recommendations:

1) The researcher recommends increasing interest in the audio materials to suit the teaching of courses in English language skills as well as English language specialty courses.

2) The researcher also recommends increasing interest in visual materials that are effective for the purposes of teaching and learning processes.

3) The researcher also advises to give more attention to audio-visual materials, where students are more interested to use these forms of teaching materials to upgrade to higher level.

4) The researcher councils to pay more attention to teaching the subject through the Internet and computer programs in the LRC to ensure that students use these materials and reach an excellent level.

5. The researcher also suggests intensifying the teaching of English language courses through more IT tools in the LRC where these courses had weak grades to very weak.

6) The researcher is also recommends to intensify the integration of the LRC at all stages of the educational process and the use of IT applications within those LRCs, while increasing the training of the LRC specialists.

7) While comparing results, it became obvious that to consider increasing the number of computers in the LRCs (number of availability points), which meets the steady increase in the number of students and faculty members at the University.

8) It is required to Increase the training and qualification of the specialists working in libraries and LRCs, which corresponds with the development in the available IT tools and the different needs of the beneficiaries. There is a need also to redefine their job descriptions to carry out specific technical and administrative tasks according to their competences and skills.

9) Within each of these findings and analyses of the study sample, it is identified that the available multimedia devices must be enhanced periodically. It is viewed also that faculty members need to participate in the selection of these educational media, as well as the selection and purchase of CDs, slides and other educational films.

\section{References}

Al Enezi, A. (2017). Technology Leadership in Saudi Schools. Education and Information Technologies, 22(3), 1121-1132. https://doi.org/10.1007/s10639-016-9477-x

Al Musawi, A., \& Amer, T. (2017). Stakeholders' Perceptions of Quality and Potential Improvements in the Learning Resources Centers at Omani Basic Education Schools. International Education Studies, 10(9), 124-140. https://doi.org/10.5539/ies.v10n9p124

Alexander, R. E. (2013). Improving Student Academic Success through Differentiated Teaching within a Specialized Learning Resource Center, ProQuest LLC. D.Ed. Dissertation, Capella University. 
Archibald, J., Roy, S., Harmel, S., \& Jesney, K. (2004). A Review of the Literature on Second Language Learning. Edmonton: Alberta Learning.

Dee, J., \& Leisyte, L. (2017). Knowledge Sharing and Organizational Change in Higher Education. Learning Organization, 24(5), 355-365. https://doi.org/10.1108/TLO-04-2017-0034

Deng, M., \& Zhu, X. (2016). Special Education Reform Towards Inclusive Education: Blurring or Expanding Boundaries of Special and Regular Education in China. Journal of Research in Special Educational Needs, 16(suppl 1), 994-998. https://doi.org/10.1111/1471-3802.12244

Eryilmaz, S., Adalar, H., \& Icinak, A. (2015). E-Learning as a Teaching Strategy Actively Used in FATIH Project. European Journal of Educational Research, 4(1), 38-47. https://doi.org/10.12973/eu-jer.4.1.38

Fellenz, M. R. (2016). Forming the Professional Self: Bildung and the Ontological Perspective on Professional Education and Development. Educational Philosophy and Theory, 48(3), 267-283.

Gropper, G. L. (2016). How to Determine if the Focus on Media Is Misplaced: (1) "Development" Functions Best When Media Selection Is Subordinate to It and (2) "Media Selection" Functions Best When It Is Subordinate to Development. Educational Technology, 56(2), 3-16.

Kurymbayev, S. G. et al. (2016). Development Principles of the Pedagogical System Aimed at Bachelor Training Based on Modern Information Technology. International Journal of Environmental and Science Education, 11(18), 11771-11790.

Lo, P., Chiu, D. K. W., \& Chu, W. (2013). Modeling Your College Library after a Commercial Bookstore? The Hong Kong Design Institute Library Experience. Community \& Junior College Libraries, 19(3-4), 59-76. https://doi.org/10.1080/02763915.2014.915186

Mendes Neto, F. M., de Carvalho Muniz, R., Filgueira Burlamaqui, A. M., \& Castro de Souza, R. (2015). An Agent-Based Approach for Delivering Educational Contents through Interactive Digital TV in the Context of T-Learning. International Journal of Distance Education Technologies, 13(2), 73-92. https://doi.org/10.4018/IJDET.2015040105

Okongo, R. et al. (2015). Effect of Availability of Teaching and Learning Resources on the Implementation of Inclusive Education in Pre-School Centers in Nyamira North Sub-County, Nyamira County, Kenya. Journal of Education and Practice, 6(35).

Ozkan, H. H. (2010). Cooperative Learning Technique through Internet Based Education: A Model Proposal. Education, 130(3), 499-508.

Rolland, J. (1983). A Look at Ontario LRCs. Canadian Library Journal, 40(3), 157-161.

Tikhonova, A. U. (2016). Overcoming the Discontinuity of Patriotic Education and Moral Development by Means of Regional Culture. International Journal of Environmental and Science Education, 11(9), 2851-2861.

Ward, V. (2017). Why, Whose, What and How? A Framework for Knowledge Mobilisers. Evidence \& Policy: A $\begin{array}{lllll}\text { Journal of Research, Debate and } & \text { Practice, }\end{array}$ https://doi.org/10.1332/174426416X14634763278725

Williams, D. C. W., \& Louisa, C. (2001). Impact of School Library Services on Achievement and Learning. Robert Gordon University.

Xu, A., \& Chen, G. (2016). A Study on the Effects of Teachers' Information Literacy on Information Technology Integrated Instruction and Teaching Effectiveness. EURASIA Journal of Mathematics, Science \& Technology Education, 12(2), 335-346. https://doi.org/10.12973/eurasia.2016.1222a

\section{Copyrights}

Copyright for this article is retained by the author(s), with first publication rights granted to the journal.

This is an open-access article distributed under the terms and conditions of the Creative Commons Attribution license (http://creativecommons.org/licenses/by/4.0/). 